\title{
On the issues of resolving a low melting combination as a definite eutectic or an elusive cocrystal: A critical evaluation
}

\author{
SURYANARAYAN CHERUKUVADA* \\ Solid State and Structural Chemistry Unit, Indian Institute of Science, Bengaluru 560 012, India \\ e-mail: chsuryan@sscu.iisc.ernet.in; chsuryan@gmail.com
}

MS received 23 August 2015; revised 17 January 2016; accepted 4 February 2016

\begin{abstract}
Cocrystals and eutectics are different yet related crystalline multi-component adducts with diverse applications in pharmaceutical and materials fields. Recently, they were shown to be alternate products of cocrystallization experiments. Whereas a cocrystal shows distinct diffraction, spectroscopic and thermal signatures as compared to parent components, the hallmark of a eutectic is its low melting nature. However, in certain cases, there can be a problem when one resorts to design a cocrystal and assess its formation vis-àvis a eutectic. In the absence of a gold standard method to make a cocrystal, it is often difficult to judge how exhaustive should the cocrystallization trials be to ensure the accomplishment of a desired/putative cocrystal. Further, a cocrystal can manifest with intermolecular interactions and/or crystal structure similar to that of its parent compounds such that the conventional diffraction and spectroscopic techniques will be of little help to conclusively infer the formation of cocrystal in the lack of single crystals. Such situations combined with low melting behavior of a combination brings the complication of resolving the combination as a cocrystal or eutectic since now both the adducts share common features. Based on the curious case of Caffeine-Benzoic acid combination, this study aims to unfold the intricate issues related to the design, formation and characterization of cocrystals and eutectics for a way forward. The utility of heteronuclear seeding methodology in establishing a given combination as a cocrystal-forming one or a eutectic-forming one in four known systems is appraised.
\end{abstract}

Keywords. Cocrystal; eutectic; supramolecular compatibility; heteronuclear seeding; phase diagram.

\section{Introduction}

Cocrystals and eutectics are multi-component crystalline solids which have varied and promising applications in pharmaceutical ${ }^{1}$ and materials fields. ${ }^{2}$ The former belongs to the class of organic/molecular materials ${ }^{1 \mathrm{a}-\mathrm{c}, \mathrm{e}, \mathrm{k}, \mathrm{m}, 3}$ and the latter to both inorganic and organic materials. ${ }^{1 \mathrm{a}, \mathrm{r}-\mathrm{u}, 2 \mathrm{a}-\mathrm{c}, \mathrm{g}}$ In a broad sense, a cocrystal is the molecular equivalent of an intermetallic compound and a eutectic is independently an inorganic and organic alloy. ${ }^{1 \mathrm{a}, \mathrm{s}, 2 \mathrm{a}, 4}$ Recently, an evolved and inclusive definition for cocrystals has been worked out by an Indo-US group according to which cocrystals are "solids that are crystalline single phase materials composed of two or more different molecular and/or ionic compounds generally in a stoichiometric ratio". 5 This definition can be slightly modified to define eutectics as "solids that are crystalline multi-phase materials composed of two or more different elements or compounds in a fixed stoichiometric ratio". The issues with respect to the structural integrity of eutectics vis-à-vis cocrystals are detailed in the Supplementary Information. The significance of cocrystals was built up in the

\footnotetext{
*For correspondence
}

1990s which had been much due to their application as 'novel solid drug forms' vis-à-vis salts. ${ }^{1 \mathrm{e}-\mathrm{q}}$ The decade long active research on cocrystals during 20012010, ${ }^{1 \mathrm{i}-\mathrm{q}}$ triggered by Etter's stupendous 'hydrogen bond rules' 6 and Desiraju's phenomenal 'supramolecular synthon'7 concept in 1990s, by various groups ${ }^{1 \mathrm{i}-\mathrm{q}, 8}$ around the globe recently culminated with their recognition as pharmaceutical materials by the United States Food and Drug Administration (US-FDA) ${ }^{1 \mathrm{~b}}$ and European Medicines Agency (EMA) ${ }^{1 \mathrm{c}}$ in the years 2013 and 2014, respectively. EMA considers a drug cocrystal to be a 'New Active Substance (NAS)', ${ }^{1 \mathrm{c}}$ if it differs in properties from parent drug, whereas US-FDA holds it to be a 'drug product intermediate' $1 \mathrm{~b}$ but not as a new drug form. On the whole, there is an opportunity to exploit cocrystals to modulate physical properties of drugs as well as to safeguard intellectual property and commercial interests both in innovation and generic drug industry. ${ }^{1 \mathrm{e}, \mathrm{k}, \mathrm{m}, \mathrm{n}, \mathrm{p}, \mathrm{v}, \mathrm{w}}$

However, despite the decade long active research on cocrystals, it is still difficult to design and desirably obtain a targeted/putative cocrystal although some success has been achieved towards this goal. ${ }^{9}$ Many unsuccessful attempts to make cocrystals were reported in the literature, ${ }^{10}$ and on the other hand they tend to be 
under-reported which can be attributed to modest understanding of the cocrystallization phenomenon itself. This situation is due to the fact that a combination of substances is subject to all permutations and combinations of various factors, both internal (related to the system - substances themselves in terms of their nature, size, shape, supramolecular compatibility, energetics) and external (surroundings - temperature, pressure, solvent, kinetics, etc.), that dictate the product outcome of the combination to be a cocrystal, molecular salt, solvate, solid solution, eutectic or a simple mixture of the substances combined among other possibilities. ${ }^{1 \mathrm{a}, \mathrm{o}, 11}$ Thus, a cocrystal and a eutectic are alternate outcomes of a cocrystallization experiment ${ }^{1 \mathrm{a}, 12,13}$ (figure S1, Supplementary Information). This author and Nangia have recently uncovered the subtle structural interrelationships among cocrystals, solid solutions and eutectics in molecular crystals. ${ }^{1 \text { a }}$ They proposed that the same crystal engineering principles, ${ }^{7}$ which form the basis to cocrystal design, can be utilized to design eutectics. Further, they have appreciated the potential of eutectics as 'novel/alternate solid drug forms' in similar lines with cocrystals, but pointed that the design studies on organic eutectics were sparse in the literature. ${ }^{1 \text { a }}$ To this effect, this author has initiated the studies, at Guru Row's research group, ${ }^{12}$ on the empirical design strategies of making cocrystals and eutectics for a given set of materials. Both cocrystals and eutectics could be reliably designed and specifically obtained in several organic systems in a mutually exclusive manner supporting that they are alternate outcomes of cocrystallization ${ }^{12}$ (relevant details are given in the Supplementary Information).

It has not escaped, during those studies, this author's attention on the 'curious case of caffeine-benzoic acid cocrystal' $^{14}$ which had been elusive for more than half a century. The first but failed attempt to make a molecular compound (cocrystal, as per the current nomenclature $)^{1 \mathrm{~g}, 3}$ of caffeine and benzoic acid was reported by Sekiguchi in $1961 .^{15}$ The binary combination exhibited 'V'-type phase diagram characteristic of a eutectic $^{1 \mathrm{a}, 2 \mathrm{a}, 10 \mathrm{c}, 12,15,16}$ system. In 2013, Bučar et al., ${ }^{14}$ were successful in making a 1:1 cocrystal of the combination by careful heteronuclear seeding ${ }^{17}$ experiments (carried out based on their computational studies which supported cocrystal formation). However, they did not perform phase diagram analysis on either the combination or the obtained cocrystal to show that it exhibits characteristic ' $W$ '-type pattern of a cocrystalforming ${ }^{10 b, 12 a, 15,16,18}$ combination. What is intriguing from the two reports is how a combination which exhibits 'eutectic-type' phase behavior (Sekiguchi's article) ${ }^{15}$ can form a cocrystal (Bučar et al.'s article) ${ }^{14}$ ?
Then, is the formation of eutectic and mutual exclusivity phenomenon an artefact? Is heteronuclear seeding technique ${ }^{14,17}$ a solution to accomplish the elusive as well as any putative cocrystal? If so, is it possible to find seeds for every desired cocrystal? Else, can one conclude non-occurrence of cocrystal for the combination and establish eutectic as alternate product ${ }^{1 \mathrm{a}, 12}$ for the same? These issues could not be recognized by Bučar et al., since the contest between cocrystal and eutectic to be an outcome of cocrystallization has been appreciated subsequent to their article in the investigations involving this author. ${ }^{1 \mathrm{a}, 12}$ The above questions need to be pursued in order to deliver a cocrystal or eutectic on demand. To answer these, at least partly, four known systems including the caffeinebenzoic acid (abbreviated here as CAF-BA) system were considered in this work to appraise the pros and cons of heteroseeding technique in establishing a combination as a cocrystal- or eutectic-forming one and thus validate the mutual exclusivity of cocrystal and eutectic. This author has previously worked on the other three systems of ornidazole-4-iodobenzoic acid, ${ }^{12 b}$ pyrazinoic acid-nicotinamide ${ }^{12 c}$ and glutarimide-3hydroxybenzoic acid $^{12 \mathrm{~d}}$ combinations which formed eutectics respectively. However, these are borderline cases with potential to form cocrystals. Hence, their analogous combinations which formed cocrystals (ornidazole-4-aminobenzoic acid, ${ }^{12 \mathrm{~b}}$ pyrazinoic acidisonicotinamide $^{12 \mathrm{c}}$ and glutarimide-3,5-dihydroxybenzoic acid ${ }^{12 \mathrm{~d}}$ ) were used for heteroseeding experiments in an attempt to obtain their cocrystals. Given heteroseeding been well-established to control the manifestation of undesired polymorphs and consequently generate elusive/targeted polymorphs, ${ }^{17,19}$ herein it was applied to facilitate the manifestation of seemingly evasive cocrystals by curtailing eutectic formation. The issues with respect to preparation and characterization of cocrystal/eutectic are detailed in the Supplementary Information. Further, the concerns/skepticism of establishing a combination as a cocrystal- or eutecticforming one and the validity of the preparation methods in resolving the issues are discussed therein.

\section{Experimental}

\subsection{Materials}

All compounds were commercially available (SigmaAldrich and Alfa Aesar, Bengaluru, India) and were used without further purification. Solvents were of analytical or chromatographic grade and purchased from local suppliers. 


\subsection{Methods and Characterization}

2.2a Liquid-assisted grinding (LAG): ${ }^{20}$ Physically mixed combinations (caffeine-benzoic acid; ornidazole4-iodobenzoic acid; pyrazinoic acid-nicotinamide; glutarimide-3-hydroxybenzoic acid), in molar ratios of about $100 \mathrm{mg}$ scale, were manually ground using a mortar-pestle for $15 \mathrm{~min}$ with $1-2 \mathrm{~mL}$ of methanol or nitromethane added. In seeding experiments, about $10 \mathrm{mg}$ of heteroseed (caffeine-2,3-difluorobenzoic acid and caffeine-salicylic acid independently for caffeine-benzoic acid; ornidazole-4-aminobenzoic acid for ornidazole4-iodobenzoic acid; pyrazinoic acid-isonicotinamide for pyrazinoic acid-nicotinamide; glutarimide-3,5-dihydroxybenzoic acid for glutarimide-3-hydroxybenzoic acid) was added and ground. The ground materials were analyzed by powder X-ray diffraction (PXRD) and thermal techniques to ascertain the formation of adduct. Cocrystal exhibited distinct PXRD pattern and melting behavior but eutectics showed only a depression in melting point compared to the parent materials. ${ }^{1 \mathrm{a}, 12}$ The formation of reported cocrystals was confirmed by matching the experimental PXRD patterns with that of the calculated profiles from X-ray crystal structures available in the Cambridge Structural Database. ${ }^{21}$

2.2b Slurry crystallization (SC): ${ }^{22}$ A suspension of physically mixed combination, in molar ratio of $200 \mathrm{mg}$ scale, was made with $2-3 \mathrm{~mL}$ methanol or nitromethane. In seeding experiments, about $20 \mathrm{mg}$ of heteroseed was added. The suspension was subjected to stirring at ambient conditions for $16-48 \mathrm{~h}$ until a little amount of solvent was still present and then was left for equilibration up till complete solvent evaporation. Airdried samples were subjected to gentle neat grinding and were analyzed by PXRD and thermal techniques.

\section{2c Powder X-ray diffraction: PXRD were} recorded on PANalytical diffractometer using $\mathrm{Cu}-\mathrm{K} \alpha$ X-radiation $(\lambda=1.5406 \AA)$ at $40 \mathrm{kV}$ and $30 \mathrm{~mA}$. Diffraction patterns were collected over $2 \theta$ range of $5-40^{\circ}$ using a step size of $0.06^{\circ} 2 \theta$ and time per step of 1 sec. X'Pert HighScore Plus (version 1.0d) ${ }^{23}$ was used to collect and plot the diffraction patterns.

2.2d Thermal analysis: DSC was performed on samples of size 1-3 mg using a Mettler Toledo DSC $822 \mathrm{e}$ module. Samples were heated @ $5^{\circ} \mathrm{C} / \mathrm{min}$ in the temperature range $30-300^{\circ} \mathrm{C}$ under ultra high pure nitrogen environment purged at $50 \mathrm{~mL} / \mathrm{min}$. Melting behavior of the combinations was analyzed on a Labindia visual melting range apparatus (MR
13300710) equipped with a camera and a LCD monitor. Physical mixtures of various molar compositions viz. $1: 1,1: 2,1: 3,1: 4,2: 1,3: 1 \& 4: 1$ were gently ground and analyzed. For cocrystal or eutectic, which is a definite stoichiometry compound, only a single melting event

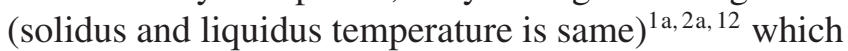
completely transforms the solid combination to molten state was observed. For non-eutectic compositions, two melting events viz. one pertaining to eutectic phase

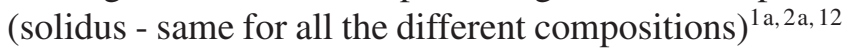
and the other to parent materials in excess (liquidus varies with composition) in the combination were observed.

\subsection{Packing diagrams}

$\mathrm{X}-\mathrm{Seed}^{24}$ was used to make packing diagrams.

\subsection{Supramolecular schematics}

ChemBioDraw Ultra (version 14$)^{25}$ was used to make supramolecular schematics.

\section{Results and Discussion}

In this study, all the four chosen systems including CAF-BA did not show any evidence of forming cocrystals and behaved as eutectic-forming systems in liquidassisted grinding (LAG) ${ }^{20}$ and slurry crystallization ${ }^{22}$ (SC) experiments without heteroseeds. The product materials were analyzed by PXRD and melting behavior (DSC \&phase diagrams as required) to validate cocrystal/eutectic formation. When a combination exhibits higher or intermediate melting as compared to its parent materials, it can be concluded that the combination is a cocrystal-forming one ${ }^{12 a}$ even if diffraction or spectroscopy measurements are inconclusive (which may happen if there is crystal packing similarity between cocrystal and parents). When a combination exhibits low melting behavior with no distinct diffraction or spectroscopic signatures, such as the case of CAF-BA (post facto there is no crystal packing similarity between it and its parents), ${ }^{14,21}$ the problem of resolving it as a definite eutectic or an inaccessible cocrystal arises. The same example shows the failure of both heating (Sekiguchi's and this study) and grinding (Bučar et al.'s and this study) methods which convincingly appear to induce molecular reorganization (by providing energy/activation) to result in cocrystal. Therefore, a technique which evades or crosses the (high) activation barrier for cocrystal nucleation and sustains the growth of cocrystal nuclei will 
Table 1. Systems selected for the study and results of heteronuclear seeding experiments.

\begin{tabular}{|c|c|c|c|c|}
\hline \multirow[b]{2}{*}{ Combination } & \multirow{2}{*}{$\begin{array}{l}\text { Nature of the } \\
\text { combination }\end{array}$} & \multicolumn{3}{|c|}{ Seeding experiments } \\
\hline & & Cocrystal seeds & LAG & $\mathrm{SC}$ \\
\hline caffeine-benzoic acid & $\begin{array}{c}\text { cocrystal by } \\
\text { Bučar et al. } 14\end{array}$ & caffeine-2,3-difluorobenzoic acid & cocrystal & cocrystal \\
\hline & & caffeine-salicylic acid ${ }^{26}$ & cocrystal & cocrystal \\
\hline $\begin{array}{l}\text { ornidazole-4- } \\
\text { iodobenzoic acid }\end{array}$ & eutectic & ornidazole-4-aminobenzoic acid & eutectic & eutectic \\
\hline $\begin{array}{l}\text { pyrazinoic acid- } \\
\text { nicotinamide }\end{array}$ & eutectic & pyrazinoic acid-isonicotinamide & eutectic & eutectic \\
\hline $\begin{array}{l}\text { glutarimide-3- } \\
\text { hydroxybenzoic acid }\end{array}$ & eutectic & glutarimide-3,5-dihydroxybenzoic acid & eutectic & eutectic \\
\hline
\end{tabular}

be helpful to resolve cocrystal/eutectic formation for a particular combination. Heteronuclear seeding ${ }^{17}$ followed by slurry crystallization, ${ }^{22}$ which resulted in the formation of long elusive CAF-BA cocrystal, ${ }^{14}$ thus has the potential to facilitate cocrystal formation. This is because the method eludes rate-limiting nucleation step through seed effect ${ }^{17}$ and sustains supersaturation for cocrystal growth through solution-mediated phase transformation. ${ }^{22 \mathrm{~b}}$ Consequently, heteronuclear seeding, followed by LAG and SC independently (detailed in Experimental Section), was undertaken in this study. The results obtained for each of the four systems subjected to heteroseeding experiments are tabulated in table 1 and the matters in each case are discussed individually as follows.

\subsection{Caffeine-benzoic acid (CAF-BA)}

Pure CAF-BA combination never yielded the cocrystal in the numerous experiments (neat grinding, LAG, sonic slurry and solution-mediated phase transformation) carried out by the four different groups involved in Bučar et al.'s article and has formed only upon seeding with cocrystals of caffeine and various fluorobenzoic acids. ${ }^{14}$ The same phenomenon of non-formation of cocrystal was also observed in this study in unseeded LAG and SC experiments. Additionally, CAF-BA system did not show any sign of cocrystal formation from its eutectic melt as analyzed by DSC (only a single endotherm was observed) and PXRD (no new or distinct peaks were observed) and manifested ' $V$ '-type pattern of a eutectic-forming system (figure 1) conforming to Sekiguchi's study. Further, solution crystallization method always resulted in falling apart of caffeine or caffeine monohydrate and benzoic acid upon crystallization which is understandable based on solution kinetics. This should be the reason for Bučar et al., to execute 'structure solution from powder diffraction' technique $^{27}$ to determine the 1:1 CAF-BA cocrystal structure in the absence of single crystals. Bučar et al., prepared the cocrystal (powder material) by using several 1:1 caffeine-fluorobenzoic acid (abbreviated here as CAF-FBA) cocrystals and pure fluorobenzoic acids respectively, as heteroseeds. Irrespective of whether being isomorphous ${ }^{28}$ to CAF-BA cocrystal or not, all their CAF-FBA cocrystals resulted in a 1:1 cocrystal of CAF-BA combination. This indicates the role of epitaxy, ${ }^{17,29}$ however isosterism between hydrogen and fluorine ${ }^{1 \mathrm{a}, 30}$ may be argued as a factor. In this context, 1:1 salicylic acid cocrystal of caffeine ${ }^{26}$ (abbreviated here as CAF-SA), whose hydroxyl group (of $\mathrm{SA}$ ) is not isosteric with hydrogen (of BA) and further non-isomorphous to CAF-BA cocrystal, was selected for heteroseeding in this work (table 1). Additionally, Bučar et al.'s caffeine-2,3-difluorobenzoic acid ${ }^{14}$ (abbreviated here as CAF-23DFBA) 1:1 cocrystal (table 1) which is isomorphous to CAF-BA cocrystal was used as a control standard. It should be noted that both these combinations (CAF-SA \& CAF-23DFBA) are structural analogues to $\mathrm{CAF}-\mathrm{BA}$ combination.

The facile formation of $1: 1$ cocrystals for several caffeine-fluorobenzoic acid (e.g., CAF-23DFBA) ${ }^{14}$ and caffeine-hydroxybenzoic acid (e.g., CAF-SA) ${ }^{26}$ combinations as against the elusive 1:1 CAF-BA cocrystal is a matter of interest on the first hand. It is found that complementarity of hydrogen bonding donoracceptor groups (or heteromolecular interactions) and continuity in the growth of heteromolecular motifs lead to the formation of cocrystal for a given combination, with eutectic being formed otherwise (see table S1, in SI). ${ }^{1 \text { a, } 12}$ In case of caffeine-fluoro/hydroxybenzoic acid (CAF-FBA/HBA) systems, there are each three complementary hydrogen bond donor (caffeine: methyl; fluoro/hydroxybenzoic acid: carboxylic acid \& $\mathrm{C}-\mathrm{H}$ ) and acceptor (caffeine: imidazole ' $\mathrm{N}$ ' \& carbonyl 'O'; fluoro/hydroxybenzoic acid: fluorine/hydroxyl ' $\mathrm{O}$ ') groups such that they can form at least three basic heteromolecular units. Carboxylic acid invariably forms 

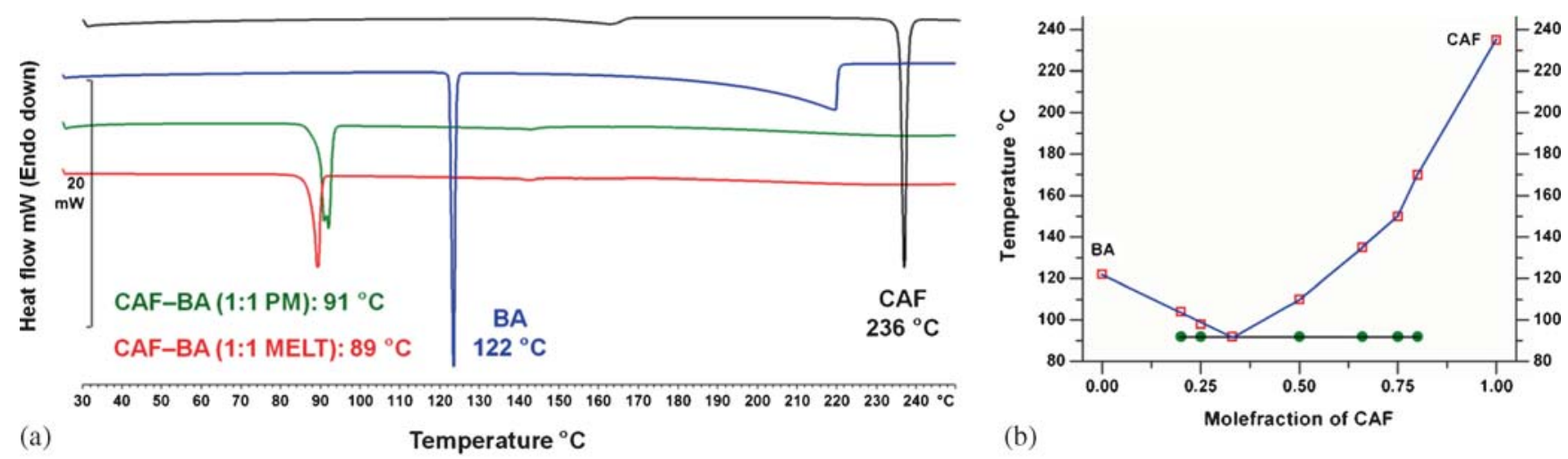

(b)

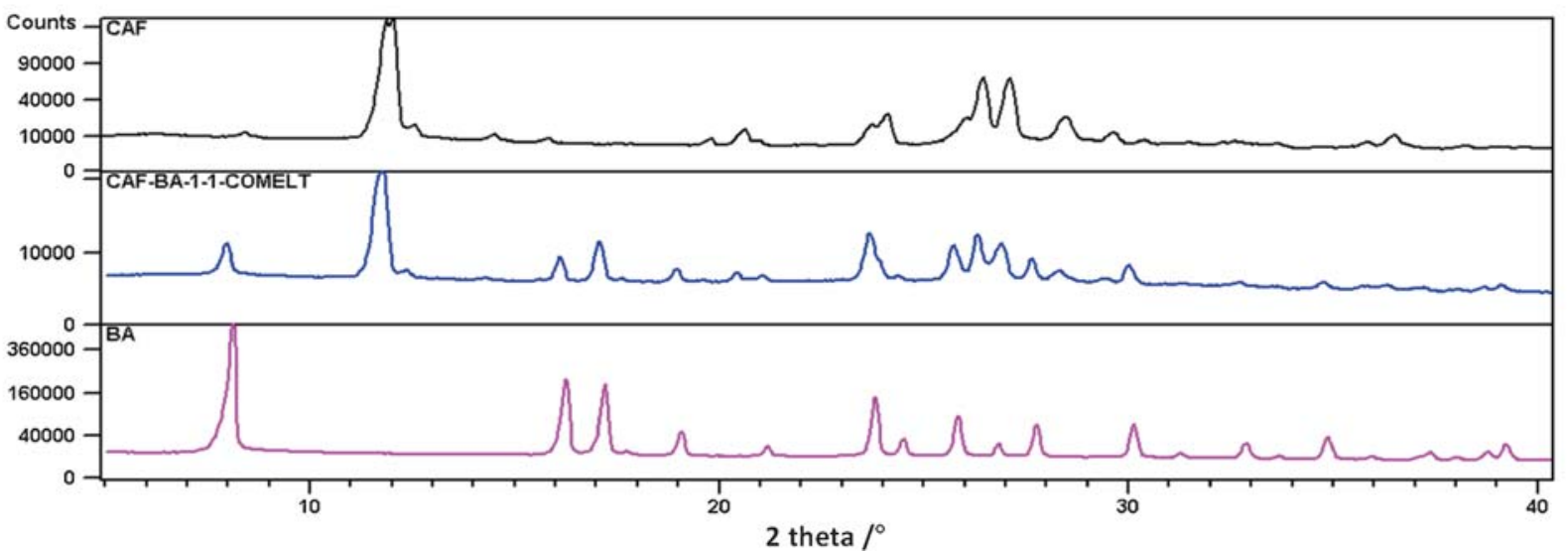

Figure 1. (a) DSC of CAF (black), BA (blue), CAF-BA 1:1 physical mixture (green) and CAF-BA 1:1 co-melted material (red). (b) Phase diagram of the system shows that it behaves as a eutectic system with a composition of 1:2 having a low melting point of about $90^{\circ} \mathrm{C}$ as compared to parent components ( $\mathrm{CAF}-236^{\circ} \mathrm{C}$; BA - $122^{\circ} \mathrm{C}$ ). Solidus points are shown as green filled circles and liquidus points as open red squares. (c) PXRD pattern of 1:1 CAF-BA co-melted material (middle) manifests as a summation of parent components (top and bottom) and does not exhibit any peaks characteristic of 1:1 cocrystal.

heterodimeric units with imidazole ${ }^{31}$ and such dimers extend into tetrameric units and so on through methylfluoro/hydroxyl interactions and $\mathrm{C}-\mathrm{H}_{(\mathrm{FBA} / \mathrm{HBA})} \cdots \mathrm{O}=$ $\mathrm{C}_{(\mathrm{CAF})}$ interactions to result in cocrystals for caffeinefluoro/hydroxybenzoic acid combinations (figure S2, in SI). The lack of free acceptor group in simple benzoic acid to complement the methyl donor of caffeine and supplement the growth of heteromolecular motifs, makes it convincing to believe that CAF-BA combination does not tend to form a cocrystal because of seemingly higher energy for the system as compared to caffeine-fluoro/hydroxybenzoic acid systems (two vs. three basic heteromolecular units). Moreover, the eutectic-type phase behavior (' $\mathrm{V}$ ' pattern) of the system strengthens the notion of non-occurrence of its cocrystal. However, the manifestation of the cocrystal (figure S2, in SI) upon heteroseeding points towards the energetics involved. The hypothesis by Bučar et al. ${ }^{14}$ is that even some of the parent fluorobenzoic acids can facilitate the formation of CAF-BA cocrystal in that they form CAF-FBA cocrystals (in situ) which act as heteroseeds and lead to CAF-BA cocrystal. Regardless of whether CAF-FBA cocrystal or its parent fluorobenzoic acid induces the formation of CAF-BA cocrystal, it is apparent that fluorine group in the form of fluorobenzoic acid brings down the energy of CAFBA system (by engaging with the free methyl group) and catalyzes cocrystal formation. To validate the role of epitaxy, apart from isosterism, in the manifestation of CAF-BA cocrystal, CAF-BA, in this study, was charged with hydroxyl ' $O$ ' acceptor in the form of caffeine-salicylic acid (CAF-SA) cocrystal which is both non-isomorphous and non-isostructural with CAF-BA cocrystal.

Both cocrystal heteroseeds of CAF-23DFBA and CAF-SA could be easily obtained, by LAG of the respective components in methanol using a mortarpestle, which indicates favorable energetics for the combinations to form cocrystals. At first, heteroseeding experiments were carried out using CAF-SA cocrystal so as to avoid the established induction of CAF-BA cocrystal in the presence of CAF-23DFBA cocrystal. Both the cocrystals resulted in the formation of CAF-BA cocrystal in independent LAG and SC experiments, upon using them as seeds, as analyzed by PXRD (figure 2) and DSC (figure 3). A phase diagram 
was constructed for $\mathrm{CAF}-\mathrm{BA}$ system by mixing the parent materials with their 1:1 cocrystal (this is because pure parent combinations manifested a ' $\mathrm{V}$ '-type pattern of eutectic as discussed earlier). One to three molar $\mathrm{CAF}$ and BA were mixed independently with 1:1 cocrystal $(2: 1,3: 1,4: 1,1: 2,1: 3$ and 1:4 CAF-BA compositions were made from $1 / 2 / 3 \mathrm{~mol} \mathrm{CAF} / \mathrm{BA}+1: 1$ CAF-BA cocrystal) and were analyzed. The characteristic 'W'-type phase diagram of a cocrystal-forming system has manifested (figure $3 \mathrm{~b}$ ). In all, both the structural analogues of CAF-BA combination facilitated the formation of cocrystal for the combination with isosterism and epitaxy having independent roles in its manifestation.

\subsection{Ornidazole-4-iodobenzoic acid (ORL-4IBA)}

The manifestation of cocrystal for ORL-4IBA ${ }^{12 b}$ system had been anticipated on the basis of facile formation of iodo-nitro heterodimeric unit ${ }^{9 \mathrm{f}}$ which can extend the potent carboxylic acid-imidazole heterodimer ${ }^{31}$ in the combination such that they make tetrameric motifs and propagate continuously building the cocrystal. However, the combination manifested as a eutectic which was rationalized based on the mismatch of induction strength complementarity between iodo (low $+I$ effect) and nitro (high $-I$ effect) groups so that they do not make a heteromeric unit and stabilize/propagate the heterotetrameric motifs ${ }^{12 \mathrm{~b}}$ (figure S3, in SI). On the other hand, ornidazole-4-aminobenzoic acid (ORL-4ABA) system, a structural analogue of ORL-4IBA, formed a 1:1 cocrystal. ${ }^{12 \mathrm{~b}}$ The strong complementarity between amine (high $+I$ effect) and nitro (high $-I$ effect) groups, unsurprisingly, facilitated cocrystal formation for the combination (ORL-4ABA) since they can form heterodimers ${ }^{1 \mathrm{~h}}$ and propagate with the carboxylic acidimidazole heterodimers (figure S3, in SI). Hence, ORL4ABA cocrystal was selected as a heteroseed to obtain the putative ORL-4IBA 1:1 cocrystal. Independent LAG and SC experiments following heteroseeding of

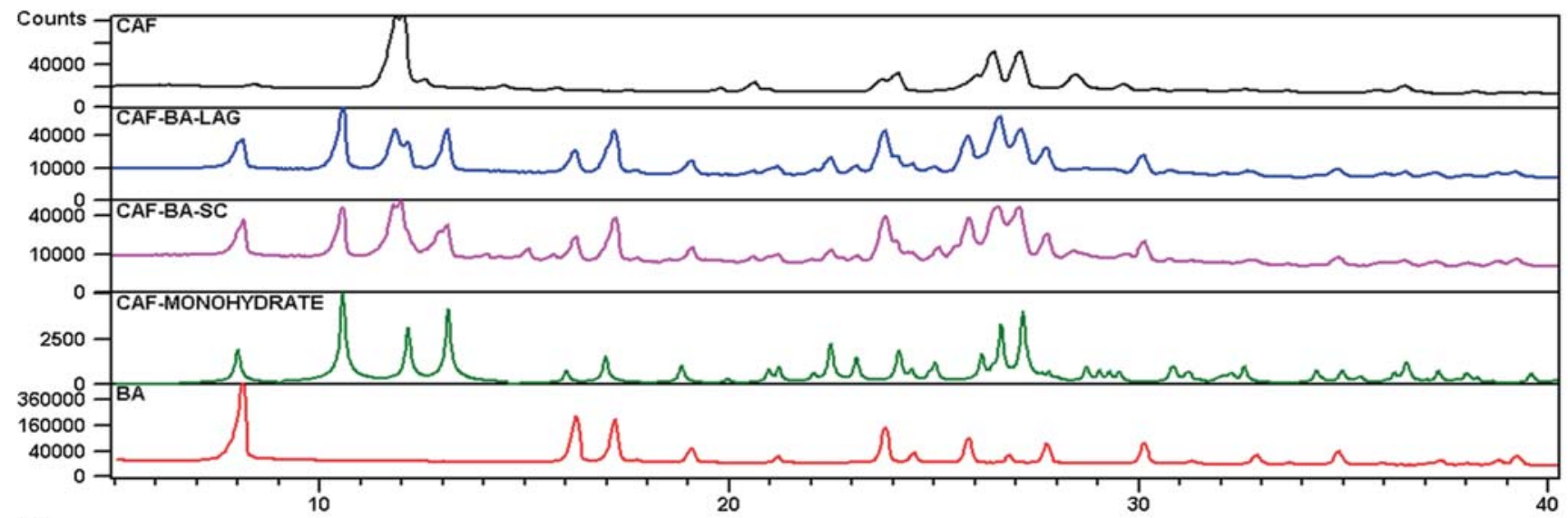

(a)

2 theta $/^{\circ}$

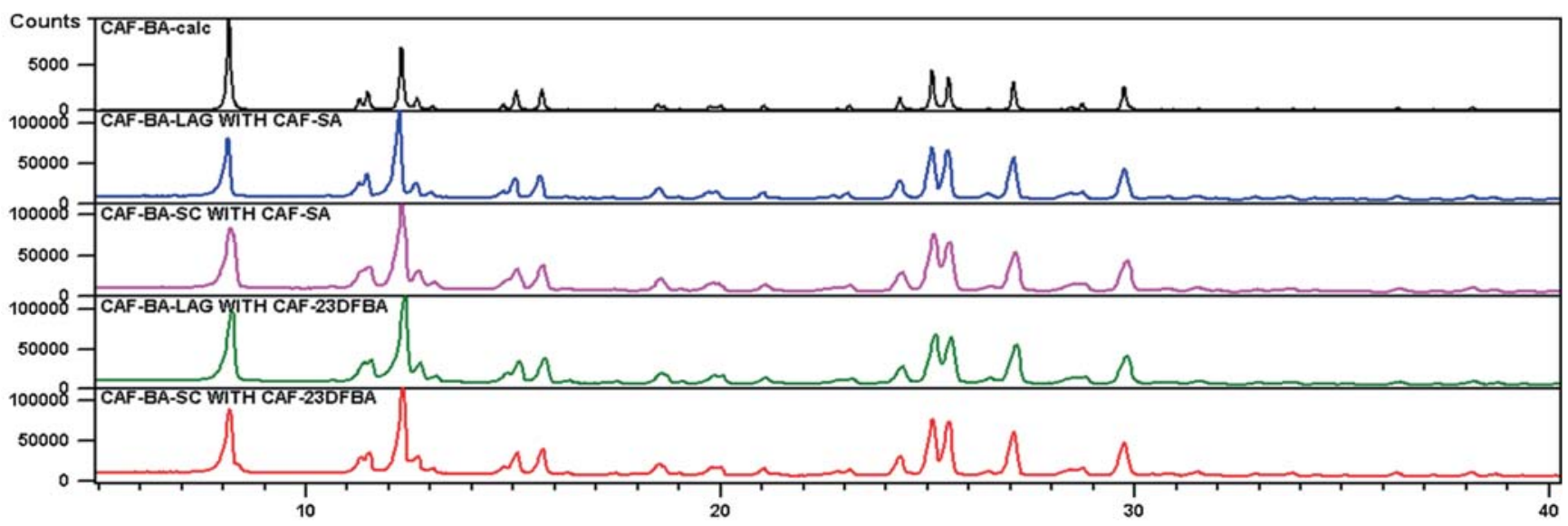

(b)

2 theta $/^{\circ}$

Figure 2. PXRD patterns of 1:1 CAF-BA combination subjected to LAG and SC (a) without and (b) with heteroseeds. In the absence of seeds, the combination just manifests as a summation of parent materials (CAF (monohydrate) + BA) and does not exhibit any peaks characteristic of its 1:1 cocrystal. 1:1 CAF-BA material from LAG and SC followed by heteroseeding matches with the calculated X-ray diffraction pattern of 1:1 CAF-BA cocrystal. 

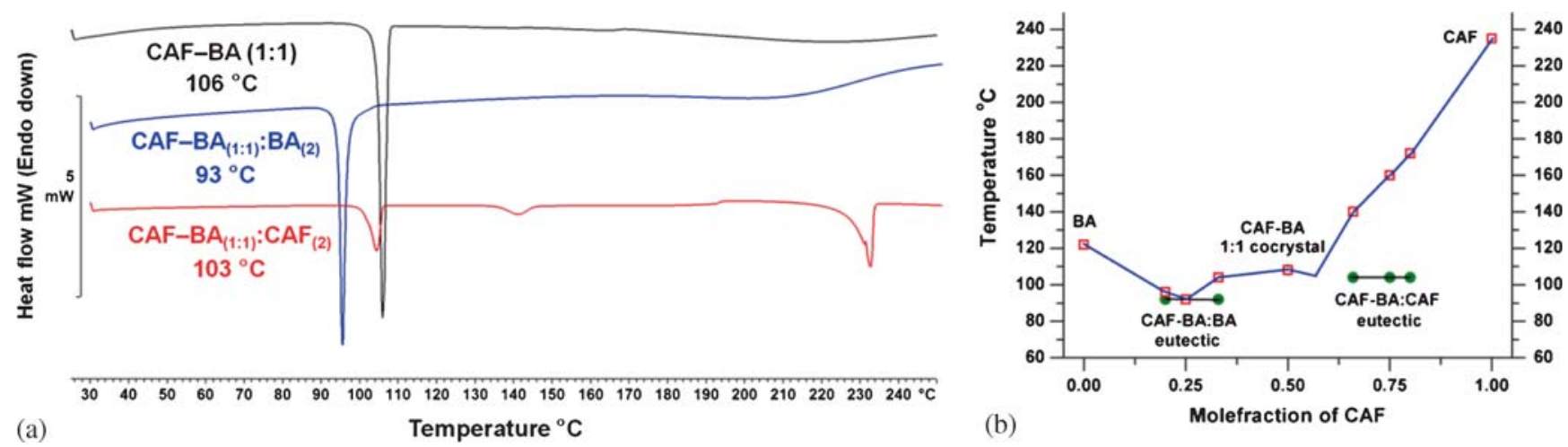

Figure 3. (a) DSC and (b) phase diagram of CAF-BA system subjected to heteroseeding show that it is a cocrystal-forming system. $1: 1$ cocrystal melts at $106^{\circ} \mathrm{C}$ and it forms eutectics with both parent materials independently $\left(\mathrm{CAF}-\mathrm{BA}: \mathrm{BA}-93^{\circ} \mathrm{C}\right.$; CAF-BA:CAF - $103^{\circ} \mathrm{C}$ ). Solidus points are shown as green filled circles and liquidus points as open red squares.

ORL-4IBA did not result in any cocrystal and corroborated the earlier study that it is a eutectic-forming system $^{12 b}$ as analyzed by PXRD (figure 4) and DSC (figure 5). It appears that either the energetics provided by the heteroseed are not sufficient or the energetics of cocrystal formation for ORL-4IBA system itself are not favorable. Thus, the seemingly feasible cocrystal manifestation upon heteroseeding with right seed, but ultimately sustenance of eutectic behavior proves that manifestation of eutectic for a given combination is not an artefact. Furthermore, it shows that eutectic is an alternate outcome of cocrystallization. ${ }^{\text {a, }, 12}$

\subsection{Pyrazinoic acid-nicotinamide (POA-NAM)}

Among the pyrazinoic acid-isomeric pyridine carboxamide combinations subjected to cocrystallization, a 1:1 cocrystal has formed for pyrazinoic acidisonicotinamide (POA-INAM) system, and pyrazinoic acid-nicotinamide (POA-NAM) and pyrazinoic acidpicolinamide (POA-PAM) systems formed eutectics. ${ }^{12 \mathrm{c}}$ It is interesting to note that POA-NAM system has more energetic advantage (of heteromolecular interactions in energy calculations) to form a cocrystal as compared to POA-INAM system, despite which it formed only a eutectic. Because of its potential to form a 1:1 cocrystal and based on the knowledge of several carboxylic acid cocrystals of nicotinamide, ${ }^{18,32}$ POA-NAM combination was subjected to heteroseeding experiments using POA-INAM cocrystal in an attempt to obtain its putative cocrystal. LAG and SC of POA-NAM with POA-INAM cocrystal seeds did not result in any cocrystal and instead corroborated the earlier study that it is a eutectic-forming system ${ }^{12 c}$ as analyzed by PXRD (figure 6) and DSC (figure 7).

The result raises the question of whether or not POA-INAM cocrystal is the right seed to make the putative POA-NAM cocrystal, although epitaxy can play a role. To answer this, one needs to understand the supramolecular compatibility of POA-pyridine carboxamide combinations. ${ }^{12 c}$ The primary supramolecular synthons of POA-pyridine carboxamide combination are carboxylic acid-pyridine, carboxylic acid-carboxamide and carboxamide-carboxamide centrosymmetric ring dimers, which have to be propagated in the lattice for a cocrystal to form. In POA-INAM system, the para location of the amide group renders the anti-NH donor free to participate in strong hydrogen bonds and thus facilitates the propagation of tetramers (composed of coplanar acid-pyridine and amide-amide dimers) leading to cocrystal formation ${ }^{12 c}$ (figure $\mathrm{S} 4$, in $\mathrm{SI})$. In case of POA-NAM combination, the anti-NH donors in the coplanar tetrameric motifs are sterically crowded and thus become unavailable for propagation (figure S4, in SI). An analysis of nicotinamide cocrystals with carboxylic acid group containing partner molecules ${ }^{18,32}$ shows that amide group has to undergo out-of-plane twisting such that the tetramers propagate through sterically freed anti-NH and form a nonsheet type architecture in the cocrystal. Since POAINAM cocrystal is a sheet structure having coplanar tetramers, ${ }^{12 \mathrm{c}}$ it does not seem to be the right seed that can provide energy for twisting of NAM's amide group and thus facilitate the formation of POA-NAM cocrystal. In all, epitaxy was unsuccessful with POA-INAM and more studies using other but related nicotinamidecarboxylic acid cocrystals need to be undertaken to realize, if at all, the POA-NAM cocrystal.

\subsection{Glutarimide-3-hydroxybenzoic acid (GM-3HBA)}

Cocrystallization studies on several glutarimidehydroxybenzoic acid combinations resulted in a eutectic for GM-3HBA system and a 1:1 cocrystal for the 


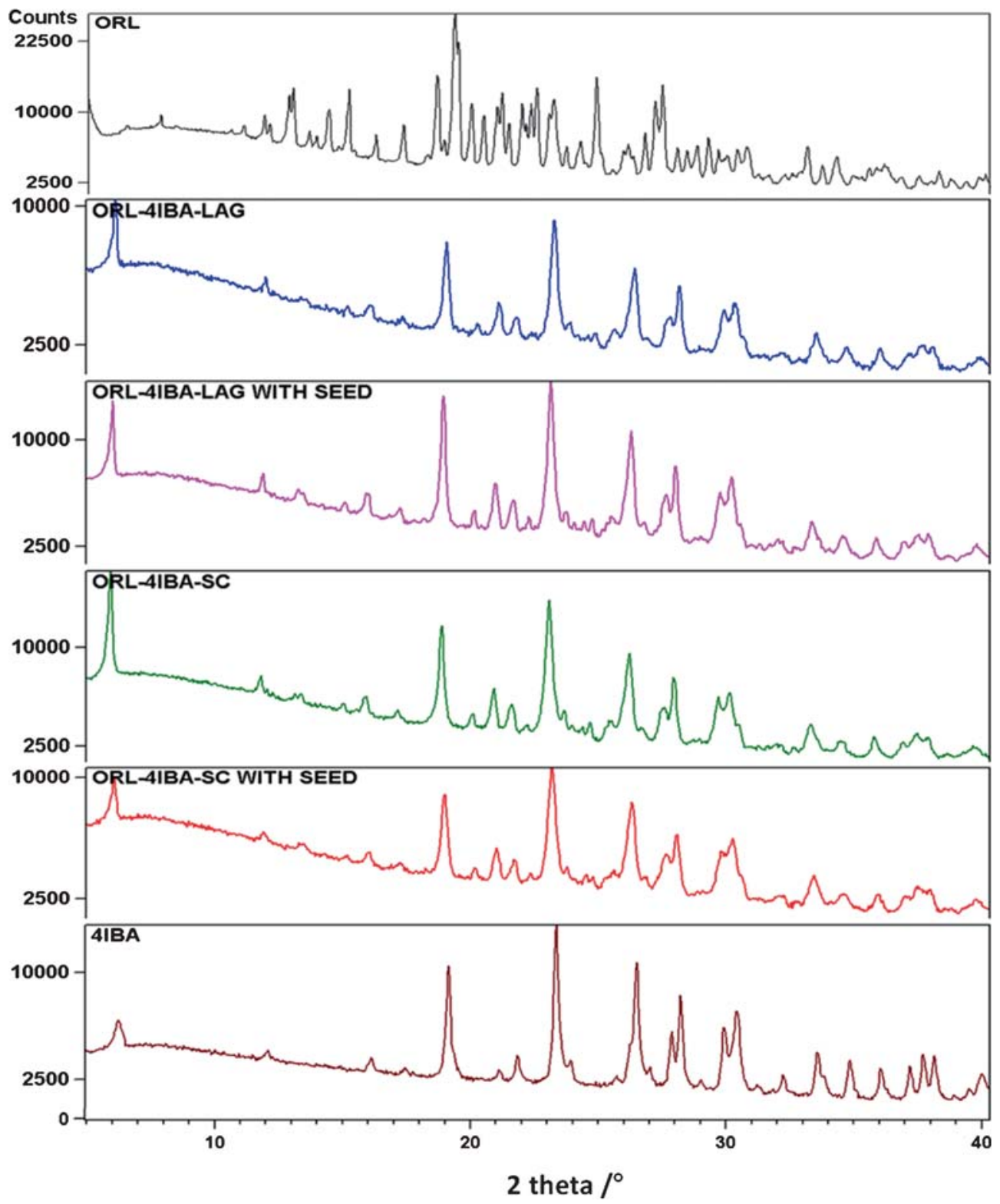

Figure 4. Comparison of PXRD patterns of 1:1 ORL-4IBA combination subjected to LAG and $\mathrm{SC}$ with and without seed shows that the combination manifests as a summation of parent materials and does not exhibit any new or distinct peaks characteristic of a cocrystal.
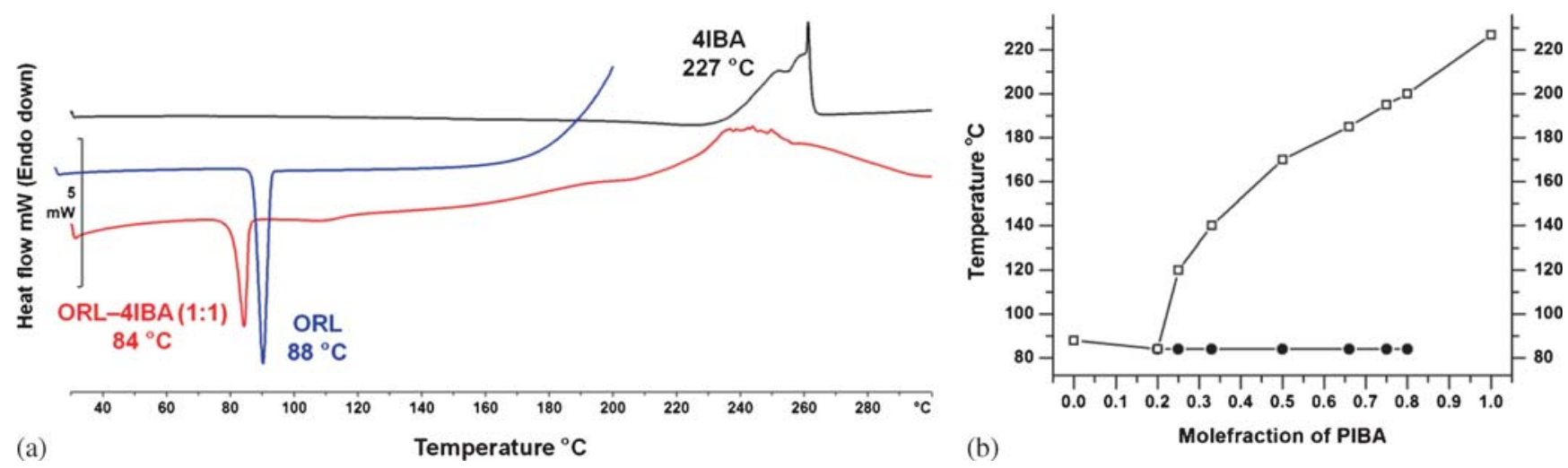

Figure 5. (a) DSC of ORL-4IBA subjected to heteroseeding shows its fusion temperature at $84^{\circ} \mathrm{C}$ which matches with that reported in (b) binary phase diagram of the system (Reproduced from Ref. ${ }^{12 b}$ with permission from the Royal Society of Chemistry, http://pubs.rsc.org/en/content/articlelanding/2014/ce/c4ce01489h\#!divAbstract). 


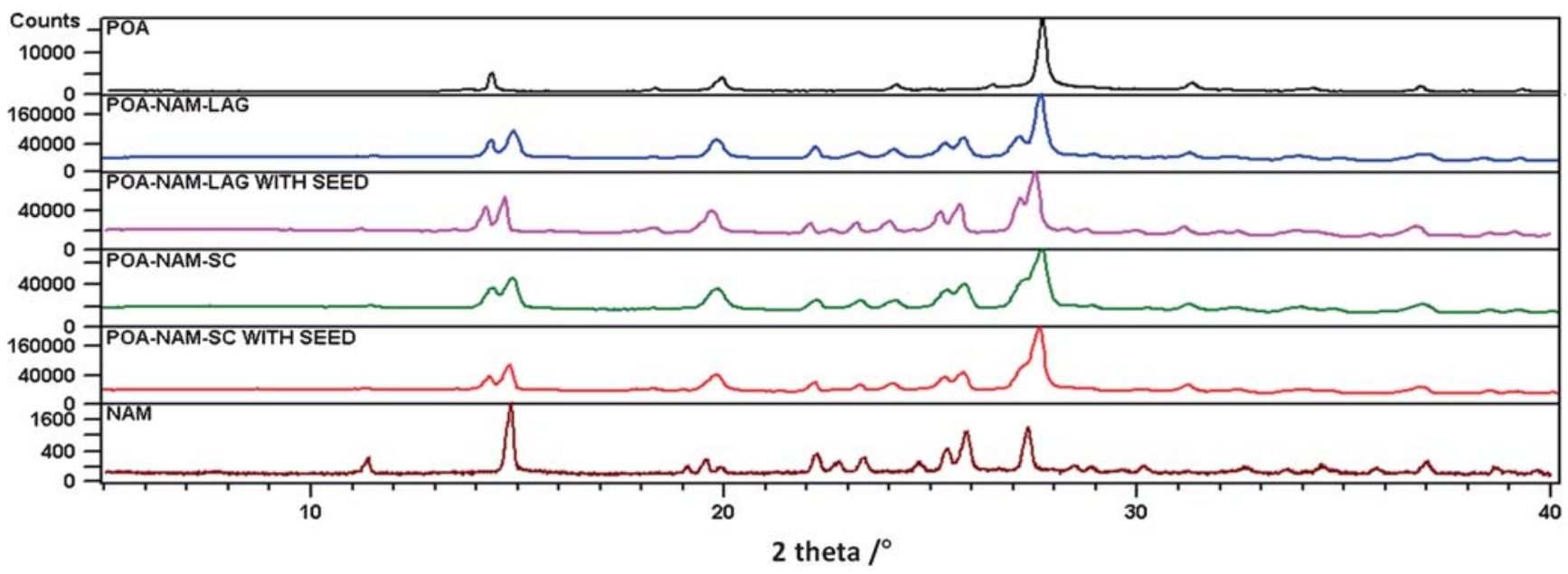

Figure 6. Comparison of PXRD patterns of 1:1 POA-NAM combination subjected to LAG and SC with and without seed shows that the combination manifests as a summation of parent materials and does not exhibit any new or distinct peaks characteristic of a cocrystal.
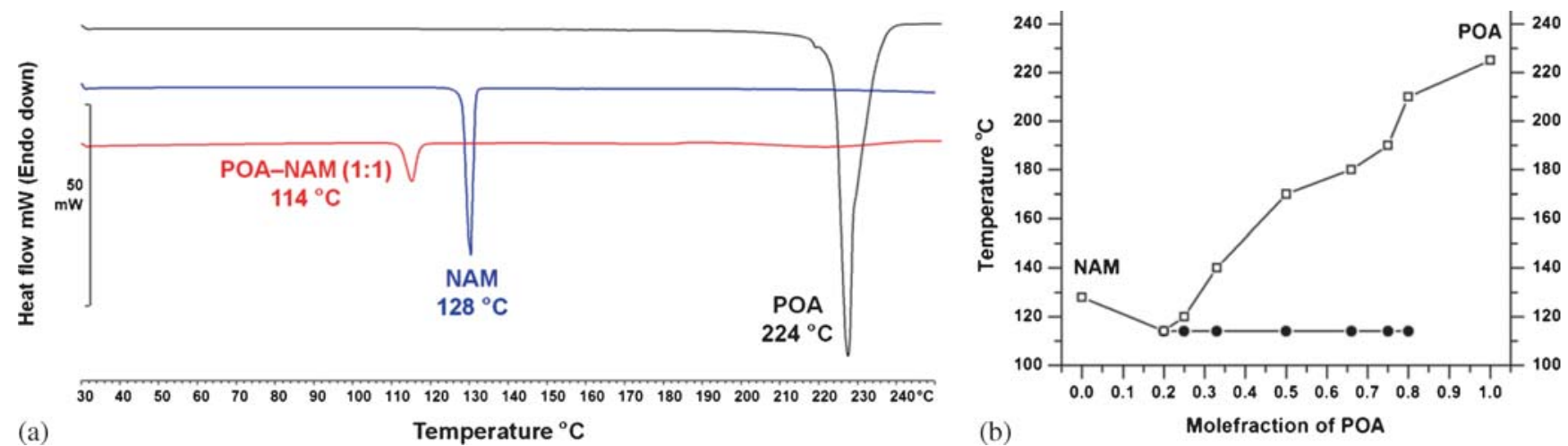

Figure 7. (a) DSC of POA-NAM subjected to heteroseeding shows its fusion temperature at $114^{\circ} \mathrm{C}$ which matches with that reported in (b) binary phase diagram of the system (Reprinted with permission from Prasad K D et al. 2015 Cryst. Growth Des. 15858 (Ref. ${ }^{12 c}$ ). Copyright 2015 American Chemical Society).

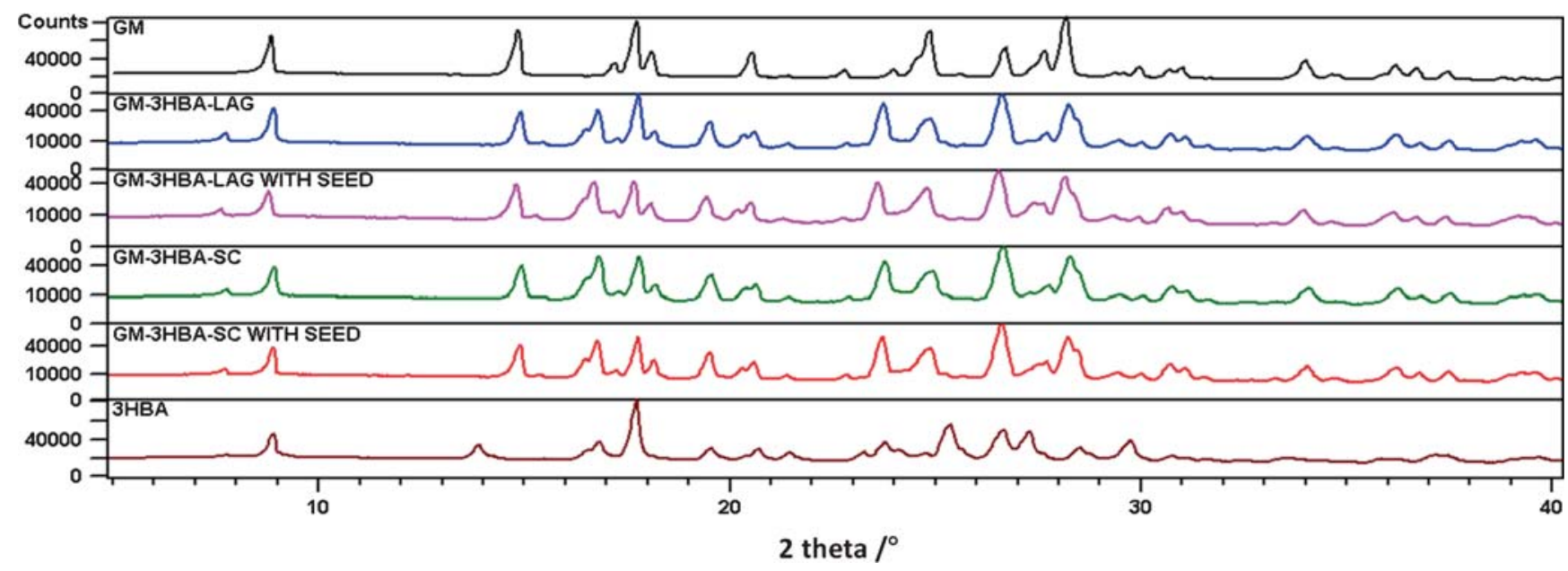

Figure 8. Comparison of PXRD patterns of 1:1 GM-3HBA combination subjected to LAG and SC with and without seed shows that the combination manifests as a summation of parent materials and does not exhibit any new or distinct peaks characteristic of a cocrystal. 

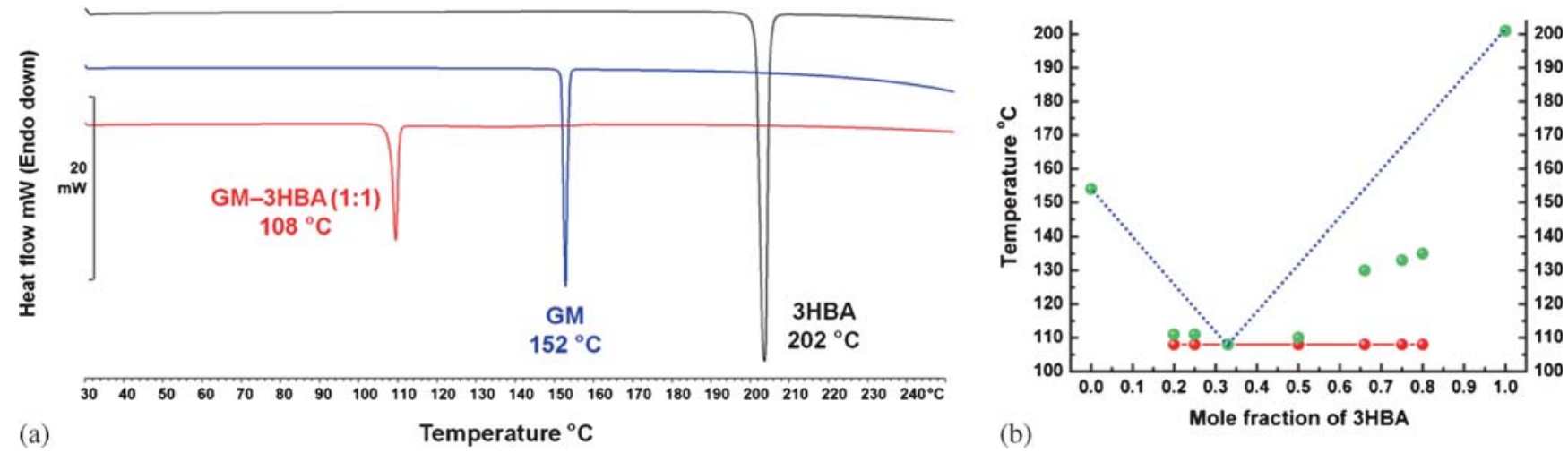

Figure 9. (a) DSC of GM-3HBA subjected to heteroseeding shows its fusion temperature at $108^{\circ} \mathrm{C}$ which matches with that reported in (b) binary phase diagram of the system (Reproduced from Ref. ${ }^{12 \mathrm{~d}}$ with permission of the International Union of Crystallography, http://journals.iucr.org/).

structurally related glutarimide-3,5-dihydroxybenzoic acid (GM-35DHBA) system. ${ }^{12 \mathrm{~d}}$ The non-occurrence of GM-3HBA cocrystal and rather formation of eutectic for the combination was reasoned based on the insufficiency of lone hydroxyl group to propagate the tetrameric motifs (composed of acid-imide and hydroxyl-imide dimers) as compared to two hydroxyl groups in case of GM-35DHBA (figure S5, in SI). The lack of additional hydroxyl group in GM-3HBA system gives way for $\mathrm{C}-\mathrm{H}_{\text {phenyl }} \cdots \mathrm{O}_{\text {imide }}$ interactions which were opined to be not energetic enough, at least in this case, to stabilize/propagate the tetrameric motifs and form a cocrystal. However, given the potential for cocrystal formation with right seeds which can facilitate the required energetics, none other than GM35DHBA cocrystal was employed for the purpose. LAG and SC of GM-3HBA followed by heteroseeding with GM-35DHBA cocrystal did not result in any cocrystal and further corroborated the earlier study that it is a eutectic-forming system ${ }^{12 \mathrm{~d}}$ as analyzed by PXRD (figure 8) and DSC (figure 9). Thus, this system also strengthens the notion of eutectic as a product alternative to cocrystal in cocrystallization ${ }^{1 \mathrm{a}, 12}$ and also that the manifestation of eutectic for a given combination is not an artefact.

\section{Conclusions}

The first-of-its-kind study towards resolving a low melting combination as a definite eutectic or an elusive cocrystal so as to unfold the intricate issues related to the manifestation of eutectic/cocrystal is reported. A supramolecular combination of two or more substances is subject to all permutations and combinations of the variables involved such that the resultant product is less predictable or variable. ${ }^{1 \mathrm{a}, 0,7 b}, 11$ The unpredictability associated with cocrystal formation is a blessing in disguise in three ways viz. (i) strengthens the patentability criterion of 'non-obviousness' for cocrystals, ${ }^{1 \mathrm{n}, 33}$ (ii) supports the notion of eutectic formation as an alternate outcome of cocrystallization ${ }^{1 \mathrm{a}, 12}$ and (iii) paves way for eutectics to be appreciated as designable materials for various applications, particularly as novel/alternate solid drug forms in similar lines as cocrystals. ${ }^{1 a}$ Although organic eutectics were known in the literature, ${ }^{1 \mathrm{~s}, 2 \mathrm{~b}, \mathrm{c}, \mathrm{g}, 34}$ there is a need for the revival of research on them so as to tap their full potential and create new options and applications. Aakeröy, in his recent paper, ${ }^{35}$ opined that cocrystal research has not yet become saturated. On the whole, the study of integral design and organization of organic eutectics and of inter-relationships between cocrystals and eutectics is a fertile research area in supramolecular solid state chemistry and facilitates better understanding of intermolecular interactions, crystallization and cocrystallization. ${ }^{\text {a, }} 12$ The phenomenon of mutual exclusivity of cocrystal and eutectic is a win-win situation in cocrystallization. To establish the manifestation of cocrystal/eutectic for a given combination in an unambiguous manner, heteronuclear seeding stands to be one of the statutory protocols in the screening arsenal. Earlier studies on unsuccessful cocrystallization attempts can be revisited for potential cocrystal formation. In this study, the same corroborated the selected four systems to be cocrystal/eutectic-forming systems irrespective of the solvent and technique employed. Nevertheless, to minimize unpleasant surprises in the future, more techniques should be incorporated into the heteroseeding methodology and make it as comprehensive as possible; seeding the molten material would be an addition in appraising the heat-stable combinations. On the other hand, finding the right heteroseeds and heteroseed impurity in the cocrystallization product 
is a matter of concern. Further, it needs to be understood, in the case of potential cocrystal-forming systems such as those studied in this work, whether the energetics facilitated even by right heteroseeds are not adequate or the energetics of the combination itself does not sustain/favor any cocrystal formation. Computational studies, ${ }^{10 \mathrm{c}, 14,36}$ crystal structure landscape studies, ${ }^{37}$ solution phase diagrams ${ }^{22 \mathrm{~b}, 38}$ and in situ monitoring, ${ }^{39}$ respectively, of cocrystallization are the ways forward and, therefore, should be undertaken more rigorously to better understand cocrystallization and to augment the strategies in the pursuit of delivering a cocrystal/eutectic on demand.

\section{Supplementary Information (SI)}

Supramolecular schematics, packing diagrams of cocrystals, preparation and characterization of cocrystals and eutectics, figures S1-S5 and table S1 are available in Supplementary Information at www.ias.ac.in/ chemsci.

\section{Acknowledgements}

I thank the University Grants Commission, India, for Dr. D. S. Kothari Postdoctoral Fellowship. I profusely thank Prof. T. N. Guru Row, Indian Institute of Science, for his encouragement to write this monograph. My special thanks to Mr. Ramesh Ganduri, Indian Institute of Science, for his help in collecting the PXRD patterns. Infrastructural facilities of the Institute are gratefully acknowledged.

\section{References}

1. (a) Cherukuvada S and Nangia A 2014 Chem. Commun. 50 906; (b) http://www.fda.gov/downloads/ Drugs/Guidances/UCM281764.pdf (accessed on 23rd August, 2015); (c) http://www.ema.europa.eu/docs/ en_GB/document_library/Scientificlguideline/2014/07/ WC500170467.pdf (accessed on 23rd August, 2015); (d) Stoler E and Warner J C 2015 Molecules 2014833 ; (e) Almarsson Ö, Peterson M L and Zaworotko M J 2012 Pharm. Pat. Anal. 3 313; (f) Cherukuvada S and Nangia A 2012 CrystEngComm 14 2579; (g) Babu N J and Nangia A 2011 Cryst. Growth Des. 11 2662; (h) Cherukuvada S, Babu N J and Nangia A $2011 J$. Pharm. Sci. 100 3233; (i) Friščić T and Jones W $2010 \mathrm{~J}$. Pharm. Pharmacol. 62 1547; (j) Aakeröy C B, Forbes $\mathrm{S}$ and Desper J 2009 J. Am. Chem. Soc. 132 17048; (k) Schultheiss N and Newman A 2009 Cryst. Growth Des. 9 2950; (1) Childs S L, Rodríguez-Hornedo N, Reddy L S, Jayasankar A, Maheshwari C, McCausland L, Shipplett R and Stahly B C 2008 CrystEngComm 10 856; (m) Thayer A N 2007 Chem. Eng. News 85 17; (n) Trask A V 2007 Mol. Pharmaceutics 4 301; (o)
Vishweshwar P, Mcmahon J A, Bis J A and Zaworotko M J 2006 J. Pharm. Sci. 95 499; (p) Almarsson Ö and Zaworotko M J 2004 Chem. Commun. 1889; (q) Childs S L, Chyall L J, Dunlap J T, Smolenskaya V N, Stahly B C and Stahly G P 2004 J. Am. Chem. Soc. 126 13335; (r) Broberg B F J and Evers H C A 1985 US Pat. 4529601; (s) Moore M D and Wildfong P L D 2009 J. Pharm. Innov. 4 36; (t) Ruecroft G, Parikh D and Prosonix Ltd. 2013 WO Pat. 2013/021199 A2; (u) Jain H, Khomane $\mathrm{K} \mathrm{S}$ and Bansal A K 2014 Cryst. Eng. Comm. 16 8471; (v) Almarsson Ö and Vadas E B 2015 Cryst. Growth Des. 15 5645; (w) Duggirala N K, Perry M L, Almarsson Ö and Zaworotko M J 2016 Chem. Commun. 52640

2. (a) Askeland D R and Fulay P P 2009 In Essentials of Materials Science and Engineering 2nd edn. (Toronto: Cengage Learning); (b) Sharma S D, Kitano H and Sagara K 2004 Res. Rep. Fac. Eng. Mie Univ. 29 31; (c) Lee L-S, Lin C-W and Kao C-H 2000 Ind. Eng. Chem. Res. 39 2068; (d) Urbanus J, Roelands C P M, Verdoes D, Jansens D J and ter Horst J H 2010 Cryst. Growth Des. 10 1171; (e) Bolton O and Matzger A J 2011 Angew. Chem. Int. Ed. 50 8960; (f) Morimoto M and Irie M 2010 J. Am. Chem. Soc. 132 14172; (g) Shilei L, Neng Z and Guohui F 2006 Energy Build. 38 708; (h) Huang X, Qin D, Zhang X, Luo Y, Huang S, Li D and Meng Q 2013 RSC Adv. 3 6922; (i) Griffini G, Brambilla L, Levi M, Castiglioni C, Zoppo M D and Turri S 2014 RSC Adv. 49893

3. Although there is no sharp organic/molecular restriction for cocrystals and several ionic cocrystals were known (Beevers C A and Cochran W 1946 Nature 157 872; Braga D, Grepioni F, Maini L, Prosperi S, Gobetto R and Chierotti M R 2010 Chem. Commun. 46 $7715)$, majority of the definitions on cocrystal ${ }^{1 \mathrm{k}}$ state it to be a multi-molecular entity and it had been termed as 'molecular compound', 'molecular complex', 'molecular crystal', 'heteromolecular crystal' etc. (Stahly G P 2009 Cryst. Growth Des. 9 4212). Molecular salt and cocrystal as the two extremes of the salt-cocrystal continuum, with the former being the ionized entity and the latter an un-ionized one, were well appreciated in the literature. $^{1 \mathrm{~b}, \mathrm{c}, \mathrm{o}, \mathrm{p}}$

4. The analogy between cocrystal and intermetallic compound brought herein should be considered in a supramolecular/structural sense and not at atomic/ molecular level where the bonding is different. Both cocrystal and intermetallic compound have distinct structural integrity as compared to their respective parent materials.

5. Aitipamula S, Banerjee R, Bansal A K, Biradha K, Cheney M L, Choudhury A R, Desiraju G R, Dikundwar A G, Dubey R, Duggirala N, Ghogale P P, Ghosh S, Goswami P K, Goud N R, Jetti R K R, Karpinski P, Kaushik P, Kumar D, Kumar V, Moulton B, Mukherjee A, Mukherjee G, Myerson A S, Puri V, Ramanan A, Rajamannar T, Reddy C M, Rodríguez-Hornedo N, Rogers R D, Row T N G, Sanphui P, Shan N, Shete G, Singh A, Sun C C, Swift J A, Thaimattam R, Thakur T S, Thaper R K, Thomas S P, Tothadi S, Vangala V R, Vishweshwar P, Weyna D R and Zaworotko M J 2012 Cryst. Growth Des. 12 2147; correction - 2012124290

6. Etter M C 1990 Acc. Chem. Res. 23120 
7. (a) Desiraju G R 1995 Angew. Chem. Int. Ed. 34 2311; (b) Desiraju G R, Vittal J J and Ramanan A 2011 In Crystal Engineering: A Textbook (Singapore: World Scientific)

8. The classification of supramolecular synthons as (i) homosynthons and (ii) heterosynthons by Walsh et al. (Walsh R D B, Bradner M W, Fleischman S, Morales L A, Moulton B, Rodríguez-Hornedo $\mathrm{N}$ and Zaworotko M J 2003 Chem. Commun. 186) has also been instrumental in catalysing the research on cocrystals

9. (a) Aakeröy C B, Beatty A M and Helfrich B A 2001 Angew. Chem. Int. Ed. 40 3240; (b) Aakeröy C B, Desper J and Urbina J F 2005 Chem. Commun. 2820; (c) Aakeröy C B, Desper J and Fasulo M E 2006 CrystEngComm 8 586; (d) Clarke H D, Hickey M B, Moulton B, Perman J A, Peterson M L, Wojtas Ł, Almarsson Ö and Zaworotko M J 2012 Cryst. Growth Des. 12 4194; (e) Aitipamula S, Wong A B H, Chow P S and Tan R B H 2013 CrystEngComm 15 5877; (f) Tothadi S and Desiraju G R 2013 Chem. Commun. 49 7791; (g) Bolla G and Nangia A 2015 Chem. Commun. 51 15578; (h) Bhogala B R and Nangia A 2008 New J. Chem. 32 800; (i) Mir N A, Dubey R and Desiraju G R 2016 IUCrJ 3, doi: 10.1107/S2052252515023945

10. (a) Lemmerer A, Bernstein J and Spackman M A 2012 Chem. Commun. 48 1883; (b) Mohammad M A, Alhalaweh A and Velaga S P 2011 Int. J. Pharmaceutics 407 63; (c) Seaton C C and Parkin A 2011 Cryst. Growth Des. 11 1502; (d) Karki S, Friščić T, Fabián L and Jones W 2010 CrystEngComm 124038

11. (a) Childs S L, Wood P A, Rodríguez-Hornedo N, Reddy L S and Hardcastle K I 2009 Cryst. Growth Des. 9 1869; (b) Childs S L, Stahly G P and Park A 2007 Mol. Pharmaceutics 4 323; (c) Sarma B, Nath N K, Bhogala B R and Nangia A 2009 Cryst. Growth Des. 9 1546; (d) In Developing Solid Oral Dosage Forms: Pharmaceutical Theory and Practice 2009 Qiu Y, Chen Y and Zhang G G Z (eds.) (New York: Academic Press); (e) Li Z J, Abramov Y, Bordner J, Leonard J, Medek A and Trask A V 2006 J. Am. Chem. Soc. 128 8199; (f) Perumalla S R and Sun C C 2013 CrystEngComm 15 5756; (g) Suresh K, Mannava M K C and Nangia A 2014 RSC Adv. 4 58357; (h) Kitaigorodsky A I 1984 In Mixed Crystals (Berlin: Springer-Verlag)

12. (a) Cherukuvada S and Row T N G 2014 Cryst. Growth Des. 14 4187; (b) Prasad K D, Cherukuvada S, Stephen L D and Row T N G 2014 CrystEngComm 16 9930; (c) Prasad K D, Cherukuvada S, Ganduri R, Stephen L D, Perumalla S and Row T N G 2015 Cryst. Growth Des. 15 858; (d) Kaur R, Gautam R, Cherukuvada S and Row T N G 2015 IUCrJ 2 341; (e) Ganduri R, Cherukuvada S and Row T N G 2015 Cryst. Growth Des. 153474

13. Cocrystallization needs to be defined broadly as the study of the formation of crystalline multi-component adducts such as cocrystals, solid solutions, eutectics, etc. and not just be reserved to cocrystals. Otherwise, in the light of eutectics as designable materials, ${ }^{1 \mathrm{a}, 12}$ one may tend to employ the term 'eutectization'.

14. Bučar D-K, Day G M, Halasz I, Zhang G G Z, Sander J R G, Reid D G, MacGillivray L R, Duera M J and Jones W 2013 Chem. Sci. 44417
15. Sekiguchi K 1961 Yakugaku Zasshi 81669

16. Davis R E, Lorimer K A, Wilkowski M A, Rivers J H, Wheeler K A and Bowers J 2004 ACA Trans. 3941

17. (a) Mitchell C A, Yu L and Ward M D 2001 J. Am. Chem. Soc. 123 10830; (b) Braga D, Maini L, de Sanctis G, Rubini K, Grepioni F, Chierotti M R and Gobetto R 2009 Chem. Eur. J. 15 1508; (c) Lang M, Grzesiak A L and Matzger A J 2002 J. Am. Chem. Soc. 12414834

18. Zhang S-W, Harasimowicz M T, de Villiers M M and Yu L 2013 J. Am. Chem. Soc. 13518981

19. (a) Davey R J, Blagden N, Potts G D and Docherty R 1997 J. Am. Chem. Soc. 119 1767; (b) Beckmann W 2000 Org. Pro. Res. Dev. 4 372; (c) Gu C-H, Chatterjee K, Young Jr. V and Grant D J W 2002 J. Cryst. Growth 235 471; (d) Thallapally P K, Jetti R K R, Katz A K, Carrell H L, Singh K, Lahiri K, Kotha S, Boese R and Desiraju G R 2004 Angew. Chem. Int. Ed. 43 1149; (e) Kelleher J M, Lawrence S E and Moynihan H A 2006 CrystEngComm 8 327; (f) Devi K R and Srinivasan K 2014 CrystEngComm 16707

20. Shan N, Toda F and Jones W 2002 Chem. Commun. 2372

21. Cambridge Structural Database, ver. 5.36, ConQuest 1.17, www.ccdc.cam.ac.uk.

22. (a) Zhang G G Z, Henry R F, Borchardt T B and Lou X 2007 J. Pharm. Sci. 96 990; (b) Rodríguez-Hornedo N, Nehm S J, Seefeldt K F, Pagán-Torres Y and Falkiewicz C J 2006 Mol. Pharmaceutics 3362

23. X'Pert HighScore Plus, The complete powder analysis tool, PANalytical B. V. 2003

24. Barbour L J, X-Seed, Graphical Interface to SHELX97 and POV-Ray, Program for Better Quality of Crystallographic Figures, University of Missouri-Columbia, Columbia, MO, 1999

25. http://scistore.cambridgesoft.com/DesktopSoftware/ ChemBioDrawUltra14Suite (accessed on 23rd August, 2015)

26. Lu E, Rodríguez-Hornedo $\mathrm{N}$ and Suryanarayanan $\mathrm{R}$ 2008 CrystEngComm 10665

27. (a) Das U, Chattopadhyay B, Mukherjee $\mathrm{M}$ and Mukherjee A K 2012 Cryst. Growth Des. 12 466; (b) Lapidus S H, Stephens P W, Arora K K, Shattock T R and Zaworotko M J 2010 Cryst. Growth Des. 104630

28. http://reference.iucr.org/dictionary/Isomorphous_ crystals (accessed on 23rd August, 2015)

29. Olmsted B K and Ward M D 2011 CrystEngComm 13 1070

30. Dikundwar A G, Venkateswarlu Ch, Chandrakala R N, Chandrasekaran S and Row T N G 2013 CrystEngComm 155403

31. Wang L, Zhao L, Liu M, Chen R, Yang Y and Gu Y 2012 Sci. China Chem. 552115

32. Bevill M J, Vlahova P I and Smit J P 2014 Cryst. Growth Des. 141438 
33. Desiraju G R 2013 J. Am. Chem. Soc. 1359952

34. (a) Rai U S and Rai R N 1998 J. Ther. Anal. 53 883; (b) Podolinsky V V, Taran Yu N and Drykin V G 1989 J. Cryst. Growth 96 445; (c) Sharma B L, Sharma N K and Bassi P S 1984 J. Cryst. Growth 67 633; (d) Singh N B and Singh N B 1978 Krist. Tech. 13 1175; (e) Rastogi R P and Bassi P S 1964 J Phys. Chem. 682398

35. Aakeröy C B 2015 Acta Crystallogr., Sect. B: Struct. Sci. 71387

36. (a) Musumeci D, Hunter C A, Prohens R, Scuderi S and McCabe J F 2011 Chem. Sci. 2 883; (b) Issa N, Karamertzanis P G, Welch G W A and Price S L 2009 Cryst. Growth Des. 9442
37. (a) Habgood M, Deij M A, Mazurek J, Price S L and ter Horst J H 2010 Cryst. Growth Des. 10 903; (b) Eccles K S, Deasy R E, Fábián L, Braun D E, Maguire A R and Lawrence S E 2011 CrystEngComm 13 6923; (c) Tothadi S and Desiraju G R 2012 Phil. Trans R. Soc. A 3702900

38. (a) Coquerel G 2014 Chem. Soc. Rev. 43 2286; (b) Manin A N, Voronin A P, Manin N G, Vener M V, Shishkina A V, Lermontov A S and Perlovich G L 2014 J. Phys. Chem. B 1186803

39. (a) Lin H-L, Zhang G-C, Hsu P-C and Lin S-Y 2013 Microchem. J. 110 15; (b) Feng Y, Dang L and Wei H 2012 Cryst. Growth Des. 122068 